\title{
PENGARUH MOTIVASI BELAJAR DAN KEMAMPUAN BERPIKIR KRITS TERHADAP HASIL BELAJAR MATEMATIKA SISWA KELAS X IPA MA.MIFTAHUL ULUM TAHUN AJARAN 2020/2021
}

\author{
Puandi Asutas $^{1}$, Tri Astindari ${ }^{2}$ Irma Noervadila ${ }^{3}$ \\ ${ }^{1,2,3}$ STKIP PGRI Situbondo, Indonesia
}

Corresponding email: puandiasutas@gmail.com

\begin{abstract}
ABSTRAK
Didalam proses belajar mengajar akan diperoleh hasil belajar. Untuk mendapatkan hasil yang optimal, proses belajar mengajar harus dilakukan dengan sadar dan sengaja serta terorganisasi secara baik. Salah satu untuk mendapatkan hasil belajar yang baik seorang siswa harus mempunyai motivasi belajar dan kemampuan berfikir kritis. Penelitian ini bertujuan untuk mengetahui 1) adakah pengaruh motivasi belajar dan kemampuan berpikir kritis terhadap hasil belajar matematika siswa kelas X IPA M.A Miftahul Ulum tahun ajaran 2020/2021. 2) untuk mengetahui adakah pengaruh motivasi belajar terhadap hasil belajar metematika siswa kelas X IPA M.A Miftahul Ulum tahun ajaran 2020/2021. 3) untuk mengetahui adakah pengarauh kemampuan berpikir kritis terhadap hasil belajar matematika siswa kelas X IPA M.A Miftahul Ulum tahun ajaran 2020/2021. Metode dalam penelitian ini menggunakan metode expost Facto.sehingga dapat disimpulkan bahwa 1) ada pengaruh motivasi belajar dan kemampuan berpikir kritis terhadap hasil belajar matematika siswa kelas X IPA M.A Miftahul Ulum tahun ajaran 2020/2021. 2) ada pengaruh motivasi belajar terhadap hasil belajar metematika siswa kelas X IPA M.A Miftahul Ulum tahun ajaran 2020/2021. 3) ada pengarauh kemampuan berpikir kritis terhadap hasil belajar matematika siswa kelas X IPA M.A Miftahul Ulum tahun ajaran 2020/2021.
\end{abstract}

Kata kunci: Motivasi belajar, Kemampuan berpikir kritis dan Hasil belajar.

\begin{abstract}
In the teaching and learning process, learning outcomes obtained. To get optimal result, the teaching and learning process carried out consciously and intentionally and well organized. One of the ways to get good learning outcomes a student must have motivation to learn and the ability to think critically. Tis study aims to find out 1 ) is there any influence of learning motivation and critical thinking skills on the mathematic learning outcomes of class X IPA M.A Miftahul Ulum in the 2020/2021 academic year. 2) to find out whether there is an effect of learning motivation on mathematic learning otcumes for student of class X IPA M.A Miftahul Ulum for the 2020/2021 academic year. 3) to find out whether there is an effect of critical thinking skills on mathematics learning outcomes for class X IPA M.A Miftahul Ulum academic year 2020/2021. The method in this study uses the
\end{abstract}


expost facto method so that it can be concluded that 1) there is an influence of learning motivation and critical thinking skill on mathematics for student of class X IPA M.A Miftahul Ulum academic year 2020/2021. 2) there is an effect of learning motivation on mathematics learning outcomes for student of class X IPA M.A Miftahul Ulum for the 2020/2021 academic year. 3) There is an influence of critical thinking ability on the mathematics learning outcomes of class X IPA M.A Miftahul Ulum 2020/2021 academic year.

Keywords: Learning motivation, Critical thinking skill and Learning outcomes.

\section{Pendahuluan}

Didalam proses belajar mengajar akan diperoleh hasil belajar. Untuk mendapatkan hasil yang optimal, proses belajar mengajar harus dilakukan dengan sadar dan sengaja serta terorganisasi secara baik. Namun pada kenyataannya, tidak semua tujuan diadakannya proses pembelajaran dapat diperoleh semudah membalikan telapak tangan. Seringkali kita temui berbagai kendala yang menghambat tercapainya tujuan pembelajaran untuk mendapatkan hasil belajar. Salah satunya adalah motivasi dan kemampuan berfikir kritis siswa.

Menurut pendapat Hamalik (Dalam Nurmala et al., 2014) motivasi adalah suatu perubahan energi dalam diri pribadi seseorang yang ditandai dengan timbulnya perasaan atau reaksi untuk mencapai tujuan. Dalam motivasi terkandung adanya keinginan, harapan, kebutuhan, tujuan, sasaran, dan insentif. Dari beberapa pendapat tersebut dapat kita tarik kesimpulkan bahwa motivasi adalah sebuah dorongan atau energi yang dapat membuat seorang siswa untuk melakukan suatu tindakan secara insentif, untuk mendapatkan sesuatu yang mereka inginkan dan yang ingin mereka capai.

Menurut.(Jumaisyaroh \& Napitupulu, 2014) berpikir kritis merupakan proses berpikir menganalisis argument dan memunculkan sebuah gagasan terhadap setiap makna untuk mengembangkan berpikir secara logis. Menurut (Yuli \& Siswono, 2016) berpikir kritis adalah sebuah proses dalam menggunakan keterampilan berpikir secara efektif untuk membantu seseorang untuk mengevaluasi, serta mengaplikasikan keputusan sesuai dengan apa yang dipercaya dan dilakukan. Dari berapat pendapat tersebut dipat diartikan berpikir kritis merupakan suatu proses berpikir secara logis untuk menganalisis dan mengevaluasi serta memunculkan sebuah gagasan atau sebuah pemikiran baru. Menurut (Komariyah \& Laili, 2018) berpikir kritis adalah proses berpikir dengan sebuah 
tujuan ingin menemukan suatu keputusan yang masuk akal yang dapat memutuskan untuk melakukan sesuatu. Dari beberapa pendapat tersebut berfikir kritis dapat diasumsikan bahwa berpikir kritis adalah suatu proses pemikiran yang penuh akan konsep dan keterampilan untuk menemukan suatu keputusan yang dapat diterima serta masuk akal.

Menurut (Sembiring \& ., 2013). Hasil belajar merupakan akibat dari proses belajar seseorang yang terkait dengan perubahan pada diri orang yang belajar. Perubahan adalah hasil dari belajar yang berupa perubahan pengetahuan, pemahaman, sikap dan tingkah laku, keterampilan dan kecakapan. Perubahan dalam arti perubahan-perubahan yang disebabkan oleh pertumbuhan yang dianggap sebagai hasil belajar. Perubahan sebagai hasil belajar bersifat relatif menetap dan memiliki potensi untuk dapat berkembang Menurut (Sjukur et al., 2012.) hasil belajar adalah suatu penilaian akhir dari proses dan pengenalan dari proses yang dilakukan berulang-ulang serta akan tersimpan dalam jangka waktu lama atau bahkan tidak akan hilang selama-lamanya karena hasil belajar turut serta dalam membentuk pribadi individu yang selalu ingin mencapai hasil yang lebih baik.

Menurut Slameto (2010:54) gejala-gejala yang mempengaruhi hasil belajar di bagi menjadi dua faktor yaitu intern dan esktern. Faktor intern adalah fantor yang berasal dari dalam diri individu yang sedang belajar, ada tiga faktor yang menjadi faktor intern dantaranya yaitu:1) Faktor jasmaniah seprti kesehatan,dan cacat tubuh.2)Faktor sekolah, yang mempengaruhi belajar mencakup metode mengajar kurikum, relasi guru dengan guru, relasi siswa dengan siswa, disiplin sekolah pengajaran dan waktu sekolah, standar pelajaran, keadaan gedung, metode belajar, dan tugas rumah.3)Faktor kelelahan yaitu kelelahan jasmani yang terlihat lemah lunglainya tubuh dan dilihat dengan adanya kelesuhan dan kebosanan,sehingga minat dan dorongan untuk menghasilkan sesuatu hilang. Faktor ekstern adalah faktor yang berada di luar individu faktor ekstern dibagi menjadi tiga yaitu:1) Faktor keluarga, siswa yang belajar akan menerima pengaruh dari keluarga berupa cara orang tua mendidik, relasi antara anggota keluarga, suasana rumah tangga dan keadaan ekonomi keluarga.2) Faktor sekolah, faktor sekolah yang mempengaruhi belajar mencakup metode mengajar, kurikulum, relasi guru dengan guru, relasi siswa dengan siswa, disiplin sekolah, pengajaran dan waktu sekolah,standar pelajaran,keadaan gedung,metode belajar, dan tugas rumah.2) Faktor masyarakat, 
faktor masyarakat yang mempengaruhi belajar yaitu berupa kegiatan siswa dalam masyarakat, media massa, teman bergaul dan bentuk kehidupan masyarakat.

\section{METODE PENELITIAN}

Metode Penelitian ini menggunakan pendekatan deskriptif kuantitatif penelitian ini bertujuan untuk menegetahui ada atau tidaknya pengaruh motivasi belajar dan berpikir kritis terhadap hasil belajar pada mata pelajaran matematika kelas X IPA MA, Miftahul Ulum semester genap tahun ajaran 2020/2021. Dalam penelitian ini menggunakan rancangan Expost Facto.Menurut Sugiyono (2016) Penelitian expost facto yaitu merupakan penelitian yang dilakukan untuk meneliti peristiwa yang telah terjadi kemudian meruntut kebelekang untuk menegetahui faktor-faktor yang dapat menimbulkan kejadian tersebut tanpa memberikan perlakuan atau manipulasi terhadap variabel yang di teliti. penentuan responden penelitian yaitu secara populasi. Menurut Lilik Aslichati dkk (2018:5.3) Populasi adalah keseluruhan elemen atau satuan yang ingin di teliti. Dalam penelitian ini populasi yang akan diteliti adalah siswa kelas X IPA MA.Miftahul Ulum. Sampel yang digunakan berjumlah 22 orang dengan teknik pengambilan sampel adalah teknik proportionate stratified random sampling merupakan teknik pengambilan sampel secara acak bagi populasi yang mempunyai anggota/unsur yang tidak homogen (heterogen) dan berstrata secara proporsional. Sedangkan untuk Teknik pengunpulan data menggunakan 1) Teknik Observasi 2) Teknik Angket 3) dokumentasi.

Teknik analisis data menggunakan. Uji validitas pada penelitian ini rumus korelasi Pearson Product Moment menurut (Imron, 2019) sbagai berikut:

$$
r_{x y}=\frac{N \sum X Y-\left(\sum X\right)\left(\sum Y\right)}{\sqrt{\left\{\left(N \sum X^{2-\left(\sum X\right)^{2}\left(N \Sigma_{Y} 2\right)}\right\}\right.}}
$$

Keterangan :

$r_{x y} \quad$ : korelasi product moment

$\sum \mathrm{x} \quad$ : Skor total dari setiap item

$\sum y \quad$ : Skor/nilai setiap item

$\mathrm{N}$ : Jumlah sampel

$\sum x y \quad$ Jumlah hasil perkalian tiap skor asli dari $\mathrm{x}$ dan $\mathrm{y}$ 
Uji reliabilitas pada penelitian ini menggunakan rumus Cronbach's Alpha sebagai berikut, Muhidin dan Abdurahman ( dalam Imron, 2019) yang rumusnya sebagai berikut:

$$
\mathrm{r}=\left(\frac{k}{k-1}\right)\left(1-\frac{\sum \sigma^{2}}{\sigma^{2} t}\right)
$$

Keterangan:

r : Reliabilitas instrumen

$\mathrm{k} \quad$ : Banyaknya butir pertanyaan atau banyaknya soal

$\sum \sigma^{2} \quad$ jumlah varians butir

$\sigma^{2} t \quad$ : varian total

a. Analisi regresi linier berganda

$$
\mathrm{Y}=\mathrm{a}+b_{1} X_{1}+b_{2} X_{2}
$$

Keterangan:

Y : Hasil belajar

a : Konstanta

$b_{1}$ dan $b_{2}$ : Koefisien Regresi

$X_{1}, X_{2} \quad$ : Variabel Independen

untuk mencari parameter a, b1 dan b2. Menurut (I Made Yuliara, 2016) sebagai berikut:

$\mathrm{a}=\mathrm{y}-\mathrm{b}_{1} \mathrm{x}_{1}-\mathrm{b}_{2} \mathrm{x}_{2}$

$\mathrm{b}_{1}=\frac{\left(\sum x_{1} y\right)\left(\sum x_{2}^{2}\right)-\left(\sum x_{2} y\right)\left(\sum x_{1} x_{2}\right)}{\left(\sum x_{1}^{2}\right)\left(\sum x_{2}^{2}\right)-\left(\sum x_{1} x_{2}\right)^{2}}$

$\mathrm{b}_{2}=\frac{\left(\sum x_{2} y\right)\left(\sum x_{1}^{2}\right)-\left(\sum x_{1} y\right)\left(\sum x_{1} x_{2}\right)}{\left(\sum x_{1}^{2}\right)\left(\sum x_{2}^{2}\right)-\left(\sum x_{1} x_{2}\right)^{2}}$

Untuk mencari nilai ( $\left.\sum X_{1}^{2}\right) ;\left(X_{2}^{2}\right) ;\left(\sum x_{1} x_{2}\right)$ dan $\left(\sum x_{2} y\right)$ adalah sebagai berikut:

$\sum x_{1}^{2}=\sum x_{1}^{2}-\frac{\left(\sum x_{1}\right)^{2}}{n} ; \quad \sum x_{2}^{2}=\sum x_{2}^{2}-\frac{\left(\sum x_{2}\right)^{2}}{n}$

$\sum x_{1}=\sum x_{1} y-\frac{\left(\sum x_{1} \sum y\right)}{n} ; \quad \sum x_{2} y=\sum x_{2} y-\frac{\left(\sum x_{2} \sum y\right)}{n}$

$\sum x_{1} x_{2}=\sum x_{1} x_{2}-\frac{\left(\sum x_{1} \sum x_{2}\right)}{n}$

b. Koefisien Korelasi Ganda

koefisien korelasi ganda digunakan untuk menghitung signifikansi hubungan antara kriterium (Y) dengan $\mathrm{X}_{1}, \mathrm{X}_{2}$. Menurut (I Made Yuliara, 2016) dengan rumus sebagai berikut: 


$$
r y(1,2)=\sqrt{\frac{b_{1} \sum x_{1} y+b_{2} \sum x_{2} y}{\sum y^{2}}}
$$

Keterangan :

$\mathrm{R}_{\mathrm{y}(1,2)}$ : Koefisien korelasi antara $\mathrm{y}$ dengan $\mathrm{x}_{1}$ dan $\mathrm{x}_{2}$

$\mathrm{b}_{1} \quad$ : Koefisien variabel $\mathrm{x}_{1}$

$\mathrm{b}_{2} \quad$ : Koefisien variabel $\mathrm{x}_{2}$

$\sum x_{1} y:$ Jumlah produk antara $\mathrm{x}_{1}$ dan $\mathrm{y}$

$\sum x_{2} y:$ Jumlah produk antara $\mathrm{x}_{2}$ dan $\mathrm{y}$

$\sum y^{2}$ : Jumlah kuadrat yang diterima oleh y

Efektifitas garis regresi digunakan untuk mengetahui pengaruh keseluruhan prediktor variabel bebas yang diteliti terhadap kriteria/variabel terikat yaitu dengan cara membandingkan $\mathrm{jkr}_{\mathrm{eg}}$ dengan $\mathrm{jkt}_{\text {otal }}$ dengan rumus sebagai berikut (Abdurrahman, 2011)

$$
\mathrm{EGR}=\frac{j k_{\text {reg }}}{j k_{\text {total }}} \times 100 \%
$$

EGR : Efektifitas garis regresi

$j k_{\text {reg }}:$ jumlah kuadrat regresi

$j k_{\text {total }}:$ jumlah kuadrat (total)

menghitung sumbangan efektif (SE) atau besar pengaruh masing-masing

prediktor ( vasriabel bebas) terhadap ( variabel terikat) dengan menggunakan rumus berikut:

$$
\begin{aligned}
& S E_{x 1}=\frac{b_{1 . \Sigma X_{1} Y}}{j k_{\text {total }}} \times 100 \% \\
& S E_{x 2}=\frac{b_{1 . \Sigma X_{2} Y}}{j k_{\text {total }}} \times 100 \%
\end{aligned}
$$

\section{Hasil dan Pembahasan}

Uji validitas motivasi belajar

$$
\begin{aligned}
r_{x y} & =\frac{n\left(\sum x y\right)-\left(\sum x\right)\left(\sum y\right)}{\sqrt{\left[n\left(\sum x^{2}\right)-\left(\sum x\right)^{2}\right]\left[n\left(\sum y^{2}\right)-\left(\sum y\right)^{2}\right]}} \\
r_{x y} & =\frac{21(4.029)-(67)(1.235)}{\sqrt{\left[21(223)-(67)^{2}\right]\left[21(74.265)-(1.235)^{2}\right]}} \\
& =\frac{84.609-82.745}{\sqrt{[4.683-4.489][1.559 .565-1.525 .225]}}
\end{aligned}
$$




$$
\begin{aligned}
& =\frac{1.864}{\sqrt{(194)(34.340)}} \\
& =\frac{1.864}{\sqrt{6.661 .960}}=\frac{1.864}{2.581,077}=0,722179
\end{aligned}
$$

Berikut ini data validitas motivasi belajar terhadap hasil belajar matematika siswa

\begin{tabular}{|c|c|c|c|}
\hline $\begin{array}{l}\text { N0. } \\
\text { Item }\end{array}$ & $\begin{array}{c}\mathbf{r} \text { hitung } \\
\text { ( Manual) }\end{array}$ & $\begin{array}{c}r \text { table } \\
(n=21, \alpha=5 \%\end{array}$ & Kesimpulan \\
\hline 1 & 0,722 & 0,456 & Valid \\
\hline 2 & 0,844 & 0,456 & Valid \\
\hline 3 & 0,655 & 0,456 & Valid \\
\hline 4 & 0,622 & 0,456 & Valid \\
\hline 5 & 0,629 & 0,456 & Valid \\
\hline 6 & 0,485 & 0,456 & Valid \\
\hline 7 & 0,548 & 0,456 & Valid \\
\hline 8 & 0,629 & 0,456 & Valid \\
\hline 9 & 0,647 & 0,456 & Valid \\
\hline 10 & 0,722 & 0,456 & Valid \\
\hline 11 & 0,548 & 0,456 & Valid \\
\hline 12 & 0,548 & 0,456 & Valid \\
\hline 13 & 0,722 & 0,456 & Valid \\
\hline 14 & 0,655 & 0,456 & Valid \\
\hline 15 & 0,844 & 0,456 & Valid \\
\hline 16 & 0,647 & 0,456 & Valid \\
\hline 17 & 0,485 & 0,456 & Valid \\
\hline 18 & 0,485 & 0,456 & Valid \\
\hline 19 & 0,844 & 0,456 & Valid \\
\hline 20 & 0,629 & 0,456 & Valid \\
\hline
\end{tabular}
kelas X IPA MA.Miftahul Ulum tahun ajaran 2020/2021

Uji validitas kemampuan berpikir kritis

$$
\begin{gathered}
r_{x y}=\frac{n\left(\sum x y\right)-\left(\sum x\right)\left(\sum y\right)}{\sqrt{\left[n\left(\sum x^{2}\right)-\left(\sum x\right)^{2}\right]\left[n\left(\sum y^{2}\right)-\left(\sum y\right)^{2}\right]}} \\
r_{x y}=\frac{21(4.058)-(67)(1.254)}{\sqrt{\left[21(221)-(67)^{2}\right]\left[21(76.048)-(1.254)^{2}\right]}}
\end{gathered}
$$




$$
\begin{aligned}
& =\frac{85.218-84.018}{\sqrt{[4.641-4.489][1.597 .008-1.572 .516]}} \\
& =\frac{1.200}{\sqrt{(152)(24.492)}} \\
& =\frac{1.200}{\sqrt{3.722 .784}} \\
& =\frac{1.200}{1.929,45174} \\
& =0,622
\end{aligned}
$$

\begin{tabular}{|c|c|c|c|}
\hline $\begin{array}{l}\text { No. } \\
\text { Item }\end{array}$ & $\begin{array}{c}\mathbf{r} \text { hitung } \\
\text { ( Manual) }\end{array}$ & $\begin{array}{c}r \text { table } \\
(n=21, \alpha=5 \%\end{array}$ & Kesimpulan \\
\hline 1 & 0,622 & 0,456 & Valid \\
\hline 2 & 0,622 & 0,456 & Valid \\
\hline 3 & 0,736 & 0,456 & Valid \\
\hline 4 & 0,680 & 0,456 & Valid \\
\hline 5 & 0,519 & 0,456 & Valid \\
\hline 6 & 0,622 & 0,456 & Valid \\
\hline 7 & 0,499 & 0,456 & Valid \\
\hline 8 & 0,519 & 0,456 & Valid \\
\hline 9 & 0,641 & 0,456 & Valid \\
\hline 10 & 0,627 & 0,456 & Valid \\
\hline 11 & 0,477 & 0,456 & Valid \\
\hline 12 & 0,499 & 0,456 & Valid \\
\hline 13 & 0,627 & 0,456 & Valid \\
\hline 14 & 0,736 & 0,456 & Valid \\
\hline 15 & 0,856 & 0,456 & Valid \\
\hline 16 & 0,741 & 0,456 & Valid \\
\hline 17 & 0,647 & 0,456 & Valid \\
\hline 18 & 0,499 & 0,456 & Valid \\
\hline 19 & 0,856 & 0,456 & Valid \\
\hline 20 & 0,519 & 0,456 & Valid \\
\hline
\end{tabular}

Uji Reliabilitas motivasi belajar

$$
\begin{aligned}
r_{11} & =\left(\frac{k}{k-1}\right)\left(1-\frac{\sum \sigma b^{2}}{\sigma^{2} t}\right) \\
r_{11} & =\left(\frac{20}{20-1}\right)\left(1-\frac{9,6018}{77,8685}\right) \\
& =(1,0526)(1-0,1233) \\
& =(1,0526)(0,8767)
\end{aligned}
$$


$=0,923$

Uji Reliabilitas kemampuan berpikir kritis

$$
\begin{aligned}
r_{11} & =\left(\frac{k}{k-1}\right)\left(1-\frac{\sum \sigma b^{2}}{\sigma^{2} t}\right) \\
r_{11} & =\left(\frac{20}{20-1}\right)\left(1-\frac{7,781}{55,53738}\right) \\
& =(1,0526)(1-0,1401) \\
= & (1,0526)(0,8599) \\
= & 0,905
\end{aligned}
$$

Menurut gay (dalam Lilik Aslichaty) suatu alat ukur dalam bidang penelitian dapat dikatakan reliabel atau dapat diterima jika nilai Alpha Cronbach 'snya diatas $\geq 0,60-0,90$. Berdasarkan tabel diatas, nilai Alpha Cronbach's untuk variabel Motivasi Belajar adalah sebesar 0,923 dan untuk variabel Berpikir Kritis nilai Alpha Cronbach's adalah sebesar 0,905 maka untuk masing-masing variabel sangat reliabel.

\section{DATA HASIL PENELITIAN}

Adapun pengumpulan data dari skor angket pengaruh motivasi belajar dan kemampuan berpikir kritis terhadap hasil belajar matematika siswa kelas X IPA M.A Miftahul Ulum tahun ajaran 2020/2021 didapatkan skor sebagai berikut

\begin{tabular}{|l|l|}
\hline$\sum x_{1}=1.235$ & $\sum x_{1} x_{2}=74.104$ \\
\hline$\sum x_{2}=1.254$ & $\sum x_{1}{ }^{2}=74.265$ \\
\hline$\sum y=1.490$ & $\sum x_{2}{ }^{2}=76.048$ \\
\hline$\sum x_{1} y=88.520$ & $\sum y^{2}=106.900$ \\
\hline$\sum x_{2} y=89.705$ & $n=21$ \\
\hline
\end{tabular}

Dari hasil perhitungan diats didapatkan sebuah data halus (skor deviasi) sebagai berikut :

$$
\begin{aligned}
& \sum \mathrm{x}_{1}{ }^{2}=1.635,2381 \\
& \sum \mathrm{x}_{2}{ }^{2}=1.166,2857 \\
& \sum \mathrm{x}_{1} \mathrm{y}=893,80952
\end{aligned}
$$




$$
\begin{aligned}
& \sum \mathrm{x}_{1} \mathrm{x}_{2}=356,8571 \\
& \sum \mathrm{x}_{2} \mathrm{y}=730,7143 \\
& \sum \mathrm{y}^{2}=1.180,952
\end{aligned}
$$

Analisi regresi berganda

$$
\begin{aligned}
\mathrm{b}_{1} & =\frac{\left(\sum x_{1} y\right)\left(\sum x_{2}^{2}\right)-\left(\sum x_{2} y\right)\left(\sum x_{1} x_{2}\right)}{\left(\sum x_{1}^{2}\right)\left(\sum x_{2}^{2}\right)-\left(\sum x_{1} x_{2}\right)^{2}} \\
& =\frac{(893,809524)(1 \cdot 166,2857)-(356,8571)(730,7143)}{(1.635,2381)(1 \cdot 166,2857)-(356,8571)^{2}} \\
& =\frac{1.042 .437,24-260.760,617}{(1.907 .154,81)-(127.347,021)} \\
& =\frac{781 \cdot 676,623}{1.779 .807,79}=0,4391 \sim 0,439 \\
b_{2} & =\frac{\left(\sum x_{2} y\right)\left(\sum x_{1}^{2}\right)-\left(\sum x_{1} y\right)\left(\sum x_{1} x_{2}\right)}{\left(\sum x_{1}^{2}\right)\left(\sum x_{2}^{2}\right)-\left(\sum x_{1} x_{2}\right)^{2}} \\
& =\frac{(730,7143)(1.635,2381)-(893,809524)(356,8571)}{(1.635,2381)\left(1.166,2857-(356,8571)^{2}\right.} \\
& =\frac{1.194 .891,86-318.962,275}{1.907 .154,81-127.347,021}=0,4921 \sim 0,492 \\
a & =\frac{\sum y}{n}-b 1 .\left(\frac{\sum x 1}{n}\right)-\left(\frac{\sum X 2}{n}\right) \\
& =\frac{1.490}{21}-0,439\left(\frac{1.235}{21}\right)-0,492\left(\frac{1.254}{21}\right)=15,735
\end{aligned}
$$

Didapat model regresi sebagi berikut: $Y=15,738+0,439 X_{1}+0,492 X_{2}$

Koefisien korelasi ganda

$$
\begin{aligned}
R_{y(1,2)} & =\sqrt{\frac{b_{1}\left(\sum x_{1} y\right)+b_{2}\left(\sum x_{2} y\right)}{\sum y^{2}}} \\
& =\sqrt{\frac{(0,4391)(893,80952)+(0,492)(730,7143)}{1.180,952}} \\
& =\sqrt{\frac{392,382379+359,511436}{1.180,952}} \\
& =\sqrt{\frac{751,8938}{1.180,952}} \\
& =\sqrt{0,637}
\end{aligned}
$$




$$
=0,7981
$$

Menghitung Efektifitas Garis Regresi

$$
\begin{aligned}
\mathrm{JK}_{\text {reg }} & =\mathrm{b}_{1}\left(\sum \mathrm{x}_{1} \mathrm{y}\right)+\mathrm{b}_{2}\left(\sum \mathrm{x}_{2} \mathrm{y}\right) \\
& =(0,439)(893,80952)+(0,492)(730,7143) \\
& =392,3824+359,5115 \\
& =751,8939 \\
\mathrm{JK}_{\text {total }} & =\sum \mathrm{y}^{2}-\frac{\left(\sum y\right)^{2}}{n} \\
& =106.900-\frac{(1.490)^{2}}{21} \\
& =106.900-105.719,048 \\
& =1.181 \\
\mathrm{EGR} & =\frac{J K_{\text {reg }}}{J K_{\text {total }}} \times 100 \% \\
= & \frac{751,8939}{1.181} \times 100 \% \\
= & 0,6367 \times 100 \% \\
= & 63,67 \%
\end{aligned}
$$

Menghitung Sumbangan Efektif

$$
\begin{aligned}
\mathrm{SEx}_{1} \% & =\frac{b_{1}\left(\sum x_{1} y\right)}{J K_{\text {reg }}} \times E G R \\
& =\frac{(0,439)(893,80952)}{751,8939} \times 63,67 \% \\
& =\frac{392,3824}{751,8939} \times 63,67 \% \\
=0,5219 & \times 63,67 \% \\
& =33,2294 \%
\end{aligned}
$$

$$
\begin{aligned}
\operatorname{SEx}_{2} \% & =\frac{b_{2}\left(\sum x_{2} y\right)}{J K_{r e g}} x E G R \\
& =\frac{(0,492)(730,7143)}{751,8939} \times 63,67 \% \\
& =\frac{359,5115}{751,8939} \times 63,67 \% \\
& =0,4781 \times 63,67 \%
\end{aligned}
$$




$$
=30,4406 \%
$$

\section{KESIMPULAN}

Berdasarkan hasil perhitungan statistik diatas dan hasil uji statistic menggunakan bantuan aplikasi spss untuk meminimalisir kesalahan peneliti,maka dapat ditarik kesimpulan untuk uji terima hipotesis (Ha) yang artinya ada pengaruh dan (Ho) yang artinya tidak ada pengaruh. Adpun pengambilan keputusan hipotesis dalam penelitian ini adah sebaga berikut:

(Ha) : Ada pengaruh antara motivasi belajar terhadap hasil belajar siswa pada mata pelajaran matematika siswa kela X IPA MA.Miftahul Ulum.

Berdasarkan hasil uji regresi berganda diatas secara manual ataupun menggunakan bingtuan aplikasi spss diketahui bahwa koefisien $\beta$ pengaruh motivasi belajar benilai positif sebesar 0,439 dan nilai thitung $>t$ tabel yaitu sebesar 3,515> 1,739 dengan tingkat signifikansi $0,002<0,005$ hal ini berarti bahwa motivasi belajar berpengaruh positif terhadap hasil belajar. Dengan demikian hipotesis (Ho) ditolak. Dan besar pengaruh antara motivasi belajar dan hasil belajar adalah sebesar 33,2294\% dan selebihnya di pengaruhi oleh variable lain yang tidak diteliti.

(Ha) : ada pengaruh kemampuan berpikir kritis terhadap hasil belajar siswa pada mata pelajaran matematika siswa kelas X IPA MA.Miftahul Ulum.

Berdasarkan hasil analisis regresi berganda menggunakan perhitungan secara manual atau menggunakan bantuan aplikasi spss dapat diketahui bahwa koefisein $\beta$ pengaruh berpikir kritis bernilai positif sebesar 0,492 dan nilai t hitung > t tabel yaitu sebesar 3,327>1,739 dengan taraf signifikansi $0,004<0,005$ hal ini berarti bahwa berpikir kritis berpengaruh positif terhadap hasil belajar. Dengan demikian hopotesis (Ho) ditolak. Dan besar pengaruh antara kemampuan berpikir kritis terhadap hasil belajar adalah sebesar 30,4406 \% dan selebihnya dipengaruhi oleh variable lain yang tidak diteliti dalam penelitian ini

(Ha) : Ada pengaruh motivasi belajar dan kemampuan berpikir kritis terhadap hasil belajar siswa pada mata pelajaran matematika siswa kelas X IPA MA.Miftahul Ulum. 
Berdasarkan hasil regresi berganda diketahui bahwa koefisien pada setiap variabel independent bernilai positif yaitu untuk $\mathrm{X}_{1}$ sebesar 0,439 dan $\mathrm{X}_{2}$ sebesar 0,492 dan nilai t hitung dari kedua variabel tersebut $>$ dari pada t table berarti dapat diartikan motivasi belajar dan kemampuan berpikir kritis mempunyai pengaruh terhadap hasil belajar. Dengan demikian hipotesis (Ho) ditolak. Dan besar pengaruh antara variabel motivasi belajar dan kemampuan berpikir kritis terhadap hasil belajar adalah sebesar 63,67 \%.

\section{DAFTAR PUSTAKA}

Aslichati Lilik dkk (2018) Metode Penelitian Sosial Penerbit Universitas Terbuka dicetak CV. Jaya Abadi Utama

I Made Yuliara Fisika, J., \& Udayana, U. (2016). Regresi linier berganda

Jumaisyaroh, T., \& Napitupulu, E. E. (2014). Peningkatan Kemampuan Berpikir Kritis Matematis dan Kemandirian Belajar Siswa SMP melalui Pembelajaran Berbasis Masalah. 5(November).

Komariyah Siti,Laili, Ahdinia Fatmala Nur (2018) Pengaruh Kemampuan Berpikir Kritis Terhadap Hasil Belajar Matematika

Nafiah, Y. N., Suyanto, W., \& Yogyakarta, U. N. (2014.). Penerapan Model Problem-Based Learning Untuk Meningkatkan Keterampilan Berpikir Kritis Dan The Application Of The Problem-Based Learning Model To Improve The Sstudents Critical Thinking. c, 125-143.

Novianti, S. D., \& Supardi, E. (2018). Kompetensi Pedagogik Guru dan motivasi Belajar Siswa Sebagai Determinan Terhadap Hasil Belajar siswa. Jurnal Pendidikan Manajemen Perkantoran, 4(1), 107. https://doi.org/10.17509/jpm.v4i1.14961

Sembiring, R. B., \& . M. (2013). Strategi Pembelajaran Dan Minat Belajar Terhadap Hasil Belajar Matematika. Jurnal Teknologi Pendidikan (JTP), 6(2), 34-44. https://doi.org/10.24114/jtp.v6i2.4996

Sjukur, S. B., Negeri, S. M. K., Kab, S., \& Bumbu, T. (2012). DAN HASIL BELAJAR SISWA TINGKAT SMK THE EFFECTS OF BLENDED LEARNING ON THE LEARNING Abstract: The Effects of Blended Learning on the Learning Motivation and Achievement Students in. 2(November 2012), 368-378.

Sugiyono (2016) Metode Penelitian Kuantitatif, Kualitatif Dan $R \& D$ Penerbit Alvabeta

Yuli, T., \& Siswono, E. (2016). Berpikir Kritis dan Berpikir Kreatif sebagai Fokus Pembelajaran Matematika. 11-26 